\title{
Improving Property Service for the City Residential Community
}

\author{
Shou-Song JIN ${ }^{a}$ Wei-Jun WU ${ }^{b}$, and Xue-Mei HUANG ${ }^{c}$ \\ Zhejiang University of Technology, Mechanical Engineering, Hangzhou, China

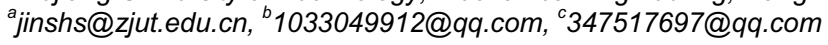

\begin{abstract}
The city residential community tends to choose a property company to provide property services and the property company should provide satisfaction services to ensure it long employed in the residential community. To raise the property service quality for a city residential community, the demand indexes for the residential community wanting and the improvement measures for the property company adopting are designed based on relevant literature review and owner questionnaire survey. The analytic hierarchy process is used to determine the demand index weight. The improvement targets of demand indexes for the residential community are planned according to the demand indexes data obtained through questionnaire survey of some residential community owners and benchmarking residential communities. And the data of improvement measures is worked out by using the quality function deployment technology to keep a sense of proportion for improving the property service.
\end{abstract}

\section{Introduction}

As people living conditions and living standards continue to improve, urban residential district owners are generally willing to hire property companies to provide residential property services. For property companies, they can seize the property service market that make owners satisfied, so many property companies and related scholars have studied how to effectively improve the quality of modern residential property services. From perspective of customer satisfaction, Tian Fengcha and Wang Xumei and so on research evaluation index system of satisfaction for property management of urban residential area and performance assessment of services for property management companies [1-3].Cheng Hongqun and Zhu Jiaolan and so on carried out the residential district property service quality evaluation and investigation [4-5].Li Qingquan and He Ping and so on researches measures to improve service quality [6-7].Based on Quality Function Deployment (QFD), Li Suhua, Li Huaqiang and Diao Yu makes technological analysis into factors to influence service quality and puts forward improvement measures [8-9].But we haven't seen the reporters which apply QFD to improve the quality of residential property services. This article will act according to circumstances and learn widely from others' strong points to analyze a city residential area of property service improvement process.

\section{Design Requirements Indicators and Improvement Measures}

In order to improve the quality of urban residential district service, we must understand what the residential district needs and what property companies do. Refereed the relevant property services satisfaction research literature and the recent State Council issued the "Property Management Regulations", etc. Randomly asked many experienced management personnel, Invited behalf of the property management personnel and a number of owners to carry out brainstorming. Specifically, it was through the data analysis, expert interviews and owners survey, used 1-5 grade Likert scale method asked hundreds of owners on behalf of dozens of property management and several experts scoring, ignored the smaller indicators of accreditation listed in the research process and added indicators that the residential area considers to be important. Finally, we got six property service demand indicators that the residential property owners on the quality of property services which including Communication skills, maintenance efficiency, garbage removal, greening layout, traffic management and the elderly activities. 


\section{Determine the Weight of the Demand Indicator}

In order to make the urban residential area owners feel satisfied, we need to improve the property needs of six demand indicators However, communication capacity (represented by CA), maintenance efficiency (ME), garbage removal (GR), greening layout (GL), traffic management (TM) and elderly activities (EA) of the six demand indicators on the degree of impact on the quality of service is different, and this difference can be expressed by the weight.

The weight calculation can be increased from 1 to 9 using the analytic hierarchy process of 1-9 scale. Invited hundreds of owner representative, dozens of physical management personnel and several experts to score for reducing the subjective influence of the individual. The importance of obtaining the six demand indicators by statistical processing is shown in TABLE 1. Used the two pairs of comparison method to fill the value of the ratio of TABLE 2, and TABLE 3. hierarchical analyzed of the root method to get the approximate weight value.

Table 1. Property Services Six Indicators Of The Importance Of Indicators

\begin{tabular}{|l|l|l|l|l|l|l|}
\hline $\begin{array}{l}\text { Demand } \\
\text { Indicators }\end{array}$ & CA & ME & GR & GL & TM & EA \\
\hline Importance & 6.5 & 7.2 & 8.6 & 6.1 & 5.0 & 4.2 \\
\hline
\end{tabular}

Table 2. Property Service 6 Comparsion Matrix of Demand Indicators

\begin{tabular}{|l|l|l|l|l|l|l|}
\hline $\begin{array}{l}\text { Demand } \\
\text { Indicators }\end{array}$ & CA & ME & GR & GL & TM & EA \\
\hline CA & 1.00 & 0.90 & 0.76 & 1.07 & 1.30 & 1.55 \\
\hline ME & 1.11 & 1.00 & 0.84 & 1.18 & 1.44 & 1.71 \\
\hline GR & 1.32 & 1.19 & 1.00 & 1.41 & 1.72 & 2.05 \\
\hline GL & 0.93 & 0.85 & 0.71 & 1.00 & 1.22 & 1.45 \\
\hline TM & 0.77 & 0.69 & 0.58 & 0.82 & 1.00 & 1.19 \\
\hline EA & 0.65 & 0.58 & 0.49 & 0.89 & 0.84 & 1.00 \\
\hline
\end{tabular}

Table 3. Analytic Hierarchy Process

\begin{tabular}{|l|l|l|l|}
\hline $\begin{array}{l}\text { Demand } \\
\text { Indicators }\end{array}$ & Multiply & Multiply6 & $\begin{array}{l}\text { Relative } \\
\text { Weight }\end{array}$ \\
\hline CA & $\begin{array}{l}1 \times 0.90 \times 0.76 \times 1.07 \\
\times 1.30 \times 1.55\end{array}$ & 1.30 & 1.55 \\
\hline ME & $\begin{array}{l}1.11 \times 1 \times 0.84 \times 1.18 \\
\times 1.44 \times 1.71\end{array}$ & 1.44 & 1.71 \\
\hline GR & $\begin{array}{l}1.32 \times 1.19 \times 1 \times 1.41 \\
\times 1.72 \times 2.05\end{array}$ & 1.72 & 2.05 \\
\hline GL & $\begin{array}{l}0.93 \times 0.85 \times 0.71 \times 1 \\
\times 1.22 \times 1.45\end{array}$ & 1.22 & 1.45 \\
\hline TM & $\begin{array}{l}0.77 \times 0.69 \times 0.58 \\
\times 0.82 \times 1 \times 1.19\end{array}$ & 1.00 & 1.19 \\
\hline EA & $\begin{array}{l}0.65 \times 0.58 \times 0.49 \\
\times 0.89 \times 0.84 \times 1\end{array}$ & 0.84 & 1.00 \\
\hline Total & & 6.20 & 1.00 \\
\hline
\end{tabular}

According to the statistical criterion, the average randomness index RI standard value of 1.24 is obtained from the statistical standard, and the maximum characteristic root $\lambda=6.06$, the consistency index $\mathrm{CI}=$ 0.012 and the consistency ratio $\mathrm{CR}=0.01<0.1$ are obtained. The weight can be used as the weight of the property service demand index.

\section{Demand Improvement Targets}

Designed questionnaires by Using the 1-5 grade Likert scale method, requested the owners of residential quarters in accordance with the requirements of the questionnaire, the communication capacity of residential quarters, maintenance efficiency, garbage removal, greening layout, traffic management and elderly activities, the satisfaction is divided into very dissatisfied with 1 point, not satisfied with 2 points, the basic satisfaction of 3 points, more satisfied with 4 points, very satisfied with 5 points, examined the surrounding two famous residential district and grasped the corresponding demand indicators' data from its property company ,finally, through the statistical processing to obtain the residential quarters and benchmarking area of the property service demand index data TABLE 4 Talked into account the application of numerical practicality, the data collected by the survey in the table to the decimal after a data to 0 or 5 rounding treatment.

The satisfaction rate of six indicators of residential property service, maintenance efficiency, garbage removal, greening layout, traffic management and old age activities are obviously lower than those of benchmarking area. Through various comparative analysis, the improvement target as shown in TABLE 4 is planned value.

Table 4. Demand Indicators for Survey Data and Improvement Goals

\begin{tabular}{|l|l|l|l|l|l|l|}
\hline $\begin{array}{l}\text { Demand } \\
\text { Indicators }\end{array}$ & CA & ME & GR & GL & TM & EA \\
\hline Residential area & 1.5 & 2.5 & 3.5 & 3.0 & 2.5 & 2.0 \\
\hline Benchmarking A & 2.0 & 3.5 & 4.0 & 3.5 & 4.0 & 3.5 \\
\hline Benchmarking B & 3.2 & 4.0 & 3.5 & 3.0 & 3.5 & 2.0 \\
\hline $\begin{array}{l}\text { Planning } \\
\text { objectives }\end{array}$ & 2.5 & 3.0 & 4.0 & 3.5 & 3.0 & 3.0 \\
\hline
\end{tabular}

\section{Calculate the Importance of Improvement Measures}

There is a causal relationship between the improvement measure value and the demand index value. By analyzing the improvement measures of the residential area, it can judge the importance of the improvement measures to improve the target. It is the process of applying the QFD quality meter to improve the importance of the improvement measures in Table 5. The improvement is the ratio to the expected improvement target and the residential area survey, and the importance of improvement is the percentage of the weight of the demand indicator and the product of the 
improvement. According to the experience of the property management experts, the intensity of the correlation between the improvement measures and the demand indicators is determined by the grade of 4 to confirm the degree of correlation between the two, divided into strong correlation 3 points, moderate correlation 2 points, weak correlation 1 , Not related to note 0 points. As there is no significant correlation between eight improvement measures such as property allocation, safety capability, established maintenance, complaint handling, environmental green, web construction, recreational facilities and traffic management, so ignore the quality table roof of the relevant types of analysis. Through the analysis of the improvement measures and the demand indicators, we can get the importance of the eight measures to improve the quality.

From Table 5, we can see the gap between the demand indicators and the improvement objectives, but also can see the improving measures that property companies need to focus on. According to the requirements of improvement target, the gap between communication skills and the improve target is the largest, the gap between traffic management and target is minimal, The most need to focus on the improvement measures is property configuration, security capacity only need a little improvement. Property company should be based on specific circumstances such as resource conditions, when it focused on the important improvement measures, the company should also be appropriate attention to non-significant improvement measures, and implement the improvement of property services.

\section{CONCLUSIONS}

Urban residential district needs high-quality property services, property companies need a comprehensive system of property services to improve the ability. Property companies for residential property services to improve the measures can be related to access to literature, consult the owners and other residential property demand indicators and property companies to improve property services measures. Applicant Analytic Hierarchy Process to determine the weight of property services demand indicators, from the residential quarters questionnaire and benchmark survey data planning property services demand indicators to improve the target, and use the QFD analysis to obtain the importance of the property service improvement measures to achieve the demand target, and to consider how to improve the property service improvement measures according to the importance of the improvement measures.

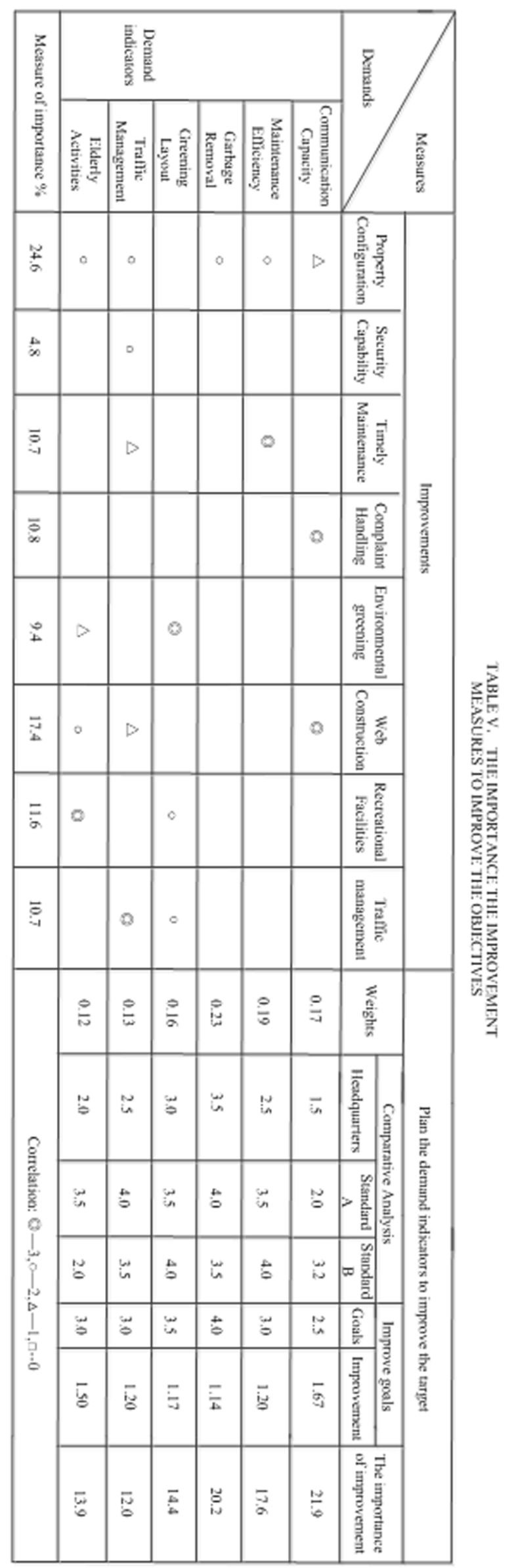




\section{References}

1. Tian Fengcha. "Evaluation model of property management owners' satisfaction in small and medium - sized cities," Science and Technology Information, vol. 8, Jun. 2011, pp. 114-115.

2. Wang Xuemei. "Study on Evaluation of Property Satisfaction of Xianhe Community". China University of Petroleum, May.2012.

3. JHK Lai. "Comparative evaluation of facility management services for housing estates," Building Services Engineering, vol. 35, Apr. 2011 , pp. 391-397.

4. Cheng Hequn,Qiu Huiling, etc. "Quality evaluation of residential property service," Luojia Management Review, vol. 2, 2013, pp. 94-103

5. Zhu Lingjiao. "Investigation on Property Management Service Quality of Residential District in Zhuhai" Value Engineering, vol. 33, Nov. 2011, pp. 75-77.

6. Li Qingquan,ZhuWei." Discussion on the improvement of property service quality based on service quality gap model']. Property Research, vol. 11, 2012, pp. 113-116.

7. He Ping, Zheng Yizhong,Sun Yanhong. "Service Competitive Behavior Based on Service Quality and Price," System Engineering Theory \& Practice, vol.34, Feb. 2014, pp. 357-364.

8. Li Suhua. "Research on service quality system of automobile technology service enterprise based on QFD," Value Engineering, vol.33, Nov. 2014, pp.145-147

9. Li HuaQiang, ZhangMeng "Research on QFD based campus courier service quality," Modern Business, vol. 15, May. 2015, pp. 258-259 